\title{
IDEALISMO Y REALISMO DE LA METAFÍSICA. \\ En torno a la revitalización del pensamiento aristotélico en Fernando Inciarte
}

\author{
Claudia Carbonell \\ Universidad de La Sabana (Colombia)
}

\begin{abstract}
Resumen: Este artículo presenta algunos de los hitos de la lectura que hace Fernando Inciarte de Aristóteles. Dicha interpretación supone un cambio de perspectiva respecto a la interpretación convencional de la metafísica aristotélica. Se señalan tres momentos de esa interpretación: el cambio de la clave de lectura metafísica de las Categorías a los libros centrales de la Metafísica; la deducción trascendental de la sustancia y de la esencia; y el redescubrimiento del lugar metafísico de la analogía típicamente aristotélica. El artículo argumenta que la interpretación de Inciarte propone una transformación del aristotelismo del que aún puede sacarse mucho rendimiento. En particular, se presentan algunos de esos rendimientos en el intento por superar el cerco culturalista de la verdad.
\end{abstract}

Palabras clave: Aristóteles, Inciarte, Categorias, Metafisica, esencia, analogía.

Idealism and Realism in Metaphysics. Around the Revitalization of the Aristotelian Thought in Fernando Inciarte

Abstract: This paper aims to present some milestones of Fernando Inciarte's reading of Aristotle. This interpretation conveys a change of perspective with respect to the conventional interpretation of Aristotelian metaphysics. Three points of this interpretation are pointed out: the change of the metaphysical reading key of Categories to that of the central books of Metaphysics; the transcendental deduction of substance and essence; and the rediscovery of the 
metaphysical place of the typically Aristotelian analogy. The paper argues that Inciarte's interpretation proposes a transformation of Aristotelianism yet to inquire. In particular, some of these achievements are presented in the attempt to overcome the culturalist enclosure of truth.

Keywords: Aristotle, Inciarte, Categories, Metaphysics, Essence, Analogy.

Recibido: 25/5/2017 Aceptado: 10/6/2017

Fernando Inciarte se definía a sí mismo como un aristotélico. En unas lecciones del semestre de invierno del año 77/78, dedicadas a Platón, comenzaba su primera clase reconociendo que tenía fama de ocuparse casi exclusivamente de Aristóteles, a la vez que traía a colación la afirmación de Hegel de que, si se tomara en serio la filosofía, no habría mejor ocupación como filósofo que dar lecciones sobre Aristóteles (Inciarte, Vorlesungen 1977/78, pro manuscripto).

El pensamiento filosófico de un autor se templa y acrisola en relación con aquellos otros pensadores con los que entra en diálogo. Este diálogo viene motivado muchas veces por cuestiones accidentales y pragmáticas, pero remite en el fondo a una afinidad de carácter que, más allá de lo moral, apunta al modo global de representarse la realidad, de procurar dar una explicación de lo que hay.

Inciarte encuentra en las claves proporcionadas por Aristóteles inspiración filosófica para los problemas filosóficos de su tiempo, así como herramientas conceptuales para buscar soluciones. A la vez y a la inversa, el bagaje de la filosofía moderna y contemporánea, en la que Inciarte se mueve como pez en el agua, sirve para descubrir posibilidades inéditas dentro del mismo pensamiento aristotélico. 
En ese intento, Aristóteles se revitaliza de una manera que no deja incólume a ninguno de los dos. En toda lectura que pretenda ser filosófica, más allá de una rehabilitación, se da una transformación. Las páginas que siguen pretenden señalar algunas de las virtualidades que Inciarte descubre en Aristóteles, fundamentales para el realismo de corte aristotélico.

\section{Teoría del significado de los signos o metafísica}

En los textos recogidos en Cultura y verdad, se evidencian algunas de las motivaciones más personales de Fernando Inciarte. "Fe y razón: sobre subjetivismo y objetivismo en la filosofía" se pregunta por la relación de la filosofía con la fe, a partir de dos textos de índole diversa: la encíclica Fides et Ratio de Juan Pablo II y un libro de Stekeler-Weithofer, que Inciarte consideraba la interpretación de Hegel de más altura y enjundia filosófica, y que lee la Ciencia de la Lógica como paradigma del giro lingüístico o semiótico de la metafísica. Como señala Inciarte, la teoría del significado de los signos, "es la sucesora en nuestros días de la metafísica tradicional. Sucesora, pero, a la vez, también, según él, destructora y superadora de la misma. La teoría del significado de los signos abarca todo el ámbito de la metafísica tradicional" (Inciarte, 2016: 165). Ese giro semiótico de la metafísica clausuraría cualquier posibilidad de ocuparse filosóficamente de la realidad, especialmente de la realidad divina.

Si bien el giro semiótico es tan moderno como lo que más, el problema aflora muy pronto en la historia de la filosofía, al menos en lo que se refiere al carácter problemático del lenguaje para acceder a lo real y, de modo más 
crítico, a lo divino. El lugar más antiguo en el que surge filosóficamente la pregunta es en el contexto de una conversación semántica que sostienen Sócrates, Hermógenes y Crátilo en el diálogo platónico que lleva el nombre de este último. Se trata de un pasaje platónico por el que Inciarte sentía una especial predilección, y en el que Hermógenes pregunta si es posible descifrar el sentido de las palabras atribuidas a lo divino, como ya han hecho respecto de las palabras referentes a las cosas humanas. A esto, responde Sócrates:

¡Por Zeus, Hermógenes! Si fuéramos sensatos, ¿s[eppe sí que tendríamos un procedimiento, el mejor: que nada sabemos sobre los dioses ni sobre los nombres que se danișél a sí mismos — pues es evidente que ellos se dan los verdaderos nombres-. Pero una segunda forma de exactitud sería llamarles, como acostumbramos en las plegarias, «cualquiera sea la forma como gusten de ser nombrados», pues ninguna otra cosa sabemos. Y pienso yo, desde luego, que es una buena costumbre. Ahora bien, si lo deseas, examinemos previniendo, por así decirlo, a los dioses que iscepino vamos a indagar nada sobre ellos mismos (pues no nos consideramos dignos de ello), sino sobre los hombres: cuálisế: era la opinión que tenían cuando les pusieron nombres. Así escaparemos de su cólera. (Crátilo 400d-401a).

Sobre este pasaje comenta Inciarte:

$\mathrm{El}$ texto todo me parece — sobre todo en boca de un griego- espléndido: tanto por lo que se refiere a la actitud ante la práctica de la religión positiva, como a la postura que exige del filósofo o simplemente - para decirlo con una palabra en boga - del hombre inquieto por explicarse las cosas. Sócrates cierra su respuesta con la observación de que esto no encierra ningún peligro. Me atrevería a decir que con absoluta razón. 
El gran peligro - desde todos los puntos de vista- en que se encuentra nuestro "hombre inquieto" no es el de querer hacerse una idea de todo, el de querer hallar una explicación —que después puede resultar más o menos verdadera- a todo lo habido y por haber. En esto no veo yo ningún peligro, sino todo lo contrario. El gran peligro, a mi modo de ver, es el de dar demasiada importancia a esa explicación, el de aferrarse a ella, el de considerarla como verdadera pura y simplemente, haciendo girar todo en torno a ella y, por consiguiente, el de cerrarse a la verdad - “a los nombres con que los dioses se pueden llamar a sí mismos”-, a la verdad que nos es dada sin que tal vez nos la lleguemos a explicar, puesto que no tiene por qué adaptarse a la idea conseguida por nuestro propio esfuerzo (Inciarte, Sobre la importancia de lo vero-simil..., pro manuscripto).

Para Inciarte, el auténtico escollo al que se enfrenta el intelecto racionalizante en relación con la verdad contenida en una religión positiva - griega o cristiana - es el peligro de aferrarse a su explicación totalizante del mundo, pretender decir la última palabra sobre la realidad, y cerrarse con ello a la verdad que está más allá de dicha explicación, que en el texto platónico remite al nombre que los dioses se dan a sí mismos, esto es, a una verdad que al hombre le es dada, no representada o figurada. Pues bien, dicho peligro conjurado una y otra vez a lo largo de la historia de la filosofía, comenzando por este texto de Platón — habría sido abrazado por la filosofía desde Hegel. Por el contrario, la actitud socrática ejemplificada en el pasaje del Crátilo lo que consigue es dejar un margen, un campo para la verdad a secas al que el hombre pueda llegar desde fuera. Es, en otros términos, el problema del culturalismo o no de la verdad. 
Pues bien, Inciarte descubre en la metafísica aristotélica un procedimiento filosófico para dejar ese margen a una verdad revelada, y en esa medida no cultural. La clave de la superación del idealismo pragmatista (culturalismo) estriba en su interpretación de Aristóteles. Ahora bien, esa superación requiere "un cambio radical de orientación con respecto a la interpretación convencional de la metafísica de Aristóteles" (Inciarte, 2016: 200-201).

¿En qué consiste ese cambio radical de orientación? ¿por qué es radical? ¿qué posibilidades filosóficas se actualizan a partir de ese cambio de interpretación?

Se trata de preguntas muy ambiciosas, que no pueden ser resueltas completamente en este escrito. Me conformo con señalar algunos hitos de ese cambio de perspectiva que constituyen, a mi juicio, una transformación del aristotelismo del que aún no hemos sacado los rendimientos posibles, y que, más allá de la rehabilitación del Aristóteles práctico de la segunda mitad del siglo XX, permitiría hablar de una revitalización del pensamiento metafísico del Estagirita, esto es, de su núcleo duro.

\section{Un cambio radical de orientación en la lectura de Aristóteles}

El cambio de orientación se funda en el lugar que se le conceda al libro de las Categorías en el pensamiento metafísico de Aristóteles. La interpretación convencional de la ontología de Aristóteles muestra una fortísima dependencia de la doctrina contenida en las Categorias, que ha traído consecuencias seculares para la llamada tradición aristotélico-tomista. El libro de las Categorias, por una parte, y los libros centrales de la Metafísica, por otra, dan 
orígenes a dos ontologías distintas, cuando no abiertamente contradictorias. Se trata de "diferencias notables entre los dos tratados, entre el relativamente simple del único libro sobre las Categorías y el de una complejidad tan desesperante a corto como iluminadora a largo plazo de los catorce libros de la Metafísica" (Inciarte, 2017: 202). Se trata, a mi juicio, de un cambio de orientación radical porque afecta a qué se entienda por la explicación última de la realidad: los elementos de la estructura lingüística o los principios del ser y del conocer.

La cuestión quizá estribe en un malentendido: Aristóteles no pretendía hacer metafísica con Categorias, que es en sentido estricto una obra lógica, precisamente el tratado que abre el Órganon aristotélico. Dicho en otros términos, Categorias presenta una teoría de los signos, de las palabras, no equiparable sin más a una metafísica, esto es, a un tratado, para usar las palabras platónicas, sobre lo verdaderamente real.

Si bien personalmente tiendo a inclinarme hacia los argumentos a favor de la inautenticidad de Categorías, considero que esto no evita el problema, no ya exclusivamente historiográfico sino filosófico, de la relación entre ambas teorías. El peso de la Wirkungsgeschichte de Categorías es innegable: el tratado ha moldeado ampliamente la concepción del ser y la sustancia de la metafísica occidental. Muchos de los problemas de interpretación de los libros centrales de la Metafísica, en la que aún se debaten los expertos aristotélicos, se deben, sobre todo, al peso de la tradición que ha leído la $M e-$ tafísica a partir de las Categorías.

Categorias es un tratado máximamente dependiente de la actitud natural, que se ve reflejada en las estructuras lingüísticas, y que no pretende sino ex- 
plicitar. De ahí que, entre otras cosas, Categorías parezca un texto más asequible y haya servido de parámetro de lectura de la Metafísica. Categorías está planteado como un estudio acerca de las formas de la predicación. En cambio, si bien en el contexto de la Metafísica afloran preocupaciones en torno a la predicación, estas inquietudes son, a juicio de Aristóteles, secundarias respecto de la pregunta por aquello que es. La metafísica de Aristóteles requiere, como viera Husserl respecto de toda actitud filosófica, del abandono de la actitud natural. Es desde la clave de ese abandono desde donde mejor puede verse la transición entre Categorias y Metafísica. Como afirma Inciarte, la metafísica de Aristóteles dista mucho del burdo realismo de la filosofía del mero sentido común (Inciarte, 2016: 205). Si por realismo alguien pretendiera entender actitud natural, la filosofía aristotélica no es realista, como por lo demás no lo sería ninguna filosofía.

La metafísica está llamada a esclarecer las estructuras fundamentales de la realidad y de la comprensión de la realidad. Para el idealismo, se trata, sin más, de lo segundo. Para Aristóteles, como queda explícito ya en el planteamiento inicial del libro III de la Metafísica, parece tratarse conjuntamente de ambas cosas: la metafísica busca, a la vez, esclarecer los principios que hacen posible el ser y el conocer. En esa medida, "toda auténtica filosofía, es decir, toda filosofía que no se conforme con el sentido común, tiene algo de idealismo... Tratar de la realidad en filosofía es, de un modo o de otro, tratar ya de su comprensión" (Inciarte, 2016: 208). Ahora bien, la diferencia estriba en que, mientras que el idealismo (el de Hegel, por ejemplo) aboga por un 
holismo total, en Aristóteles estaríamos ante un holismo sustancial ${ }^{1}$. Para el problema de Inciarte en Cultura y verdad, esto es para la cuestión de la relación entre filosofía y vida, filosofía y fe, el holismo sustancial deja un portillo, ese margen del que hablábamos al principio, abierto a un acceso inmediato a la realidad, el de la fe entre otros, mientras que el holismo total por definición lo clausura.

Aunque parezca una perogrullada, el núcleo de un holismo sustancial está precisamente en su comprensión de la sustancia. Y ahí es donde una interpretación de la metafísica de Aristóteles dependiente de Categorías resulta devastadora. Según la escolástica de cuño aristotélico, la sustancia sensible se estructura como compuesto de materia prima y forma sustancial, y en ella inhieren las formas accidentales. De esta manera, la forma sustancial se entiende como lo que hace que una cosa sea lo que es, una especie de causa eficiente interna, ella misma inmóvil, que recibe pasivamente sucesivas determinaciones. Si hay algo que a la modernidad le resulte oscuro y extraño del aristotelismo es precisamente tal concepto de "forma sustancial": "un ente filosófico desconocido para mî" según Descartes y, para Spinoza, una doctrina ingenua y frívola (Pasnau, 2011: 549). Por otra parte, la idea de forma, al no tener impacto causal en la realidad física, resulta, para la ciencia moderna, un dogma anticuado del pensamiento metafísico (Buchheim, 2008). Ahora bien, como ha mostrado Inciarte, tal desarrollo de la teoría aristotélica no es

${ }^{1}$ El término "holismo sustancial" lo toma Inciarte de Thomas Scaltsas (1994), si bien difiere en puntos esenciales de su interpretación. 
el único posible. Se trata de una prosecución dependiente de privilegiar la lectura de Categorías sobre los libros centrales de la Metafísica.

Inciarte aboga por una lectura independiente y unitaria de la Metafísica. Al debatido problema de la unidad de la metafísica, responde proponiendo una unidad caracterizada por el entreveramiento de los principios epistemológicos y la sustancia como el único principio ontológico. Así, la lectura de la metafísica aristotélica que postula es la de una metafísica de principios. Según este autor, no es casual el orden en el que hemos recibido los libros de la Metafísica: después del planteamiento del problema en el libro III, la solución aristotélica parte de la consideración de los primeros principios (libro IV) a través de la exposición de la teoría de la sustancia (libros VII-IX) hasta alcanzar aquella actividad que no tiene ningún contenido específico (libro XII). Según la interpretación inciarteana, que en este punto se inspira en Schelling, la metafísica de Aristóteles debe leerse como un camino marcado por un sucesivo abandono de contenido. Sólo a través de un proceso de purificación y eliminación de todo contenido ideal puede buscarse aquel principio que no es nada más que su propia actividad y que, por ello, escapa al cerco significativo, esto es, a nuestras ideas. Me fijaré sólo en los pasos iniciales y centrales de este recorrido. Y, como corolario, señalaré cómo tal abandono sucesivo de contenido en el que consiste la metafísica opera de acuerdo con una herramienta conceptual que, desde Aristóteles, se llama analogía, y cuya comprensión requiere también superar la interpretación tradicional. 
Idealismo y realismo de la metafísica

\section{De las categorías a la esencia}

Tomando prestada la terminología kantiana, Inciarte habla de tres sucesivas deducciones trascendentales en Aristóteles: deducción de categorías, deducción de la sustancia y deducción de la esencia (Inciarte, 2016: 213-233; 244-257)2. Este paso triple conduce desde la distinción de significaciones, en el plano de la idealidad, al reconocimiento de la necesidad de una sustancia y, en último término, de la esencia de dicha sustancia como lo propiamente real. No es este el lugar para reconstruir en su totalidad la argumentación de Inciarte. Me interesa más bien mostrar cómo en dicha argumentación se esclarecen algunas cuestiones intensamente debatidas en la discusión académica sobre Aristóteles, a la vez que se abre el camino (se rompe el cerco) para un acceso inmediato a lo real. Sobra decir que esta inmediatez no es, en el caso de la filosofía, inicial, sino el resultado final de un arduo esfuerzo por

\footnotetext{
${ }^{2}$ Inciarte había tratado llamado ya "deducción trascendental" a este procedimiento en Aristóteles en un artículo publicado en Anuario Filosófico en 1993, recogido en Flamarique, 2004. Sin embargo, en la segunda parte de Cultura y Verdad, en los capítulos 6 y 8, que recoge textos trabajados a finales de los años 90 , la tesis y sus implicaciones encuentran un desarrollo más amplio. El término "deducción trascendental" significa para Inciarte aquí "exposición de las condiciones necesarias para que se pueda dar una comunicación verbal, racional o, simplemente, entre personas humanas". (Inciarte, 2016: 213, n.25). El uso de esta terminología, "deducción trascendental", para referirse a un procedimiento aristotélico, así como "realismo trascendental" para hablar del realismo aristotélico que se sigue de esta interpretación, son usados también por B. Hafemann en su libro Aristoteles' Transzendentaler Realismus, producto de una disertación realizada bajo la dirección de F. Inciarte.
} 
romper el cerco lingüístico, esto es, una inmediatez que es fundamentalmente mediatez superada.

En la justificación que Aristóteles hace del Principio de $\mathrm{No}^{-}$ Contradicción, Inciarte descubre esta deducción trascendental de las categorías y de la sustancia; esto es, la estrategia aristotélica de mostrar la necesidad de las categorías, en primer término, en un segundo momento, de la sustancia. Lo primero estriba en admitir la pluralidad de significaciones, de conceptos, primer paso necesario para la comunicación racional. Pero ello no basta. Según Inciarte, no hay algo así como un espacio lógico donde se articulen aleatoriamente los contenidos significativos, sino que se requiere reglas de combinación que exigen la postulación de la distinción entre sustancia y accidentes, esto es, entre el sujeto y sus sucesivas determinaciones. El lugar de concurrencia es la sustancia real, no ya un espacio lógico vacío:

...la lógica de la comunicación depende en último término de sustancias reales, cuya existencia rompe el cerco de la comunicación de significados. De la misma manera, según Aristóteles, no es que el principio de no contradicción valga porque sin él la comunicación no sería posible: su validez trasciende también el cerco de la comunicación. En esto se basa la posibilidad de una verdad objetiva independiente de todo multiculturalismo y, ya antes, de todo culturalismo.

Sin embargo, la mera distinción de contenidos significativos y de su regla de combinación no basta para dar cuenta del movimiento, en cuya explicación se juega la elucidación de lo real y no sólo de nuestras ideas. Esto es, la pluralidad de significaciones y sus reglas combinatorias se mueven en el ámbito de la idealidad (de los contenidos significativos), no en el ámbito de 
lo real. Los conceptos no tienen propiedades: si los tuvieran, entonces estarían sujetos a cambio, pero dejarían de ser lo que cada uno es. Es preciso admitir también reglas de conexión temporal entre los diversos significados. Como dice Inciarte:

Permanecer a través del tiempo significa seguir siendo lo mismo no tanto a pesar del cambio ("a pesar del tiempo") sino cambiando ("al pasar tiempo"). Con otras palabras, permanecer idéntico a través del tiempo requiere poder ir adquiriendo (y perdiendo) nuevas propiedades. $\mathrm{Y}$ esto no lo puede hacer un concepto (un contenido significativo, abstracto, ideal) sino sólo una sustancia (concreta, real), es decir, algo capaz de modificación o, lo que es lo mismo, capaz de tener propiedades (no sólo clasificativas sino también descriptivas). (Inciarte, 2004: 39).

El genuino realismo metafísico de Aristóteles está en aceptar la inevitabilidad de los sustancias como sujeto de movimiento: si no aceptamos las sustancias reales como sujetos de accidentes reales, esto es, como aquello cuya identidad real estriba en cambiar, no sólo no podríamos hablar con sentido, sino que no estaríamos en capacidad de referirnos a lo real.

Como es bien sabido, Categorias denomina sustancias primeras a aquellas realidades "que no están en un sujeto, ni se predican de un sujeto" (2a10), es decir, objetos individuales como un hombre particular o un caballo particular, como Sócrates o Corisco. Aquellas cosas que se predican de estas sustancias como universales, se consideraban allí sustancias segundas. De acuerdo con la lectura simétrica entre estructuras lingüísticas y estructuras metafísicas que se sigue de considerar Categorías un tratado metafísico, los accidentes inhieren en el sujeto (en bypokeimenoi), que permanece como el 
núcleo duro inmóvil. Ahora bien, tal lectura simétrica no es posible, como muestra que Aristóteles abandone $-\mathrm{o}$ transforme, que es otra manera de abandonar- los rendimientos semióticos de Categorías en la Metafisica.

El panorama filosófico que presenta la Metafísica es distinto, e incluso puede decirse que desafía la actitud natural. Allí desaparece la denominación de sustancia segunda, la doctrina de la inherencia no juega ningún papel y la sustancia entendida como forma tiene prioridad respecto de la sustancia entendida como materia o como el compuesto de ambas. La cuestión clave en este contexto es que ya no es el individuo concreto (el objeto de la experiencia sensible) el que cumple los requisitos para ser sustancia en sentido estricto, sino que ha de ser la forma o la esencia. Así, el eìdos de Metafísica VII no es la especie a la que pertenece un individuo concreto, sino la forma individual, la sustancia entendida como esencia, como único sujeto posible del cambio.

Esto es, no basta con deducir la necesidad de un sujeto que sirva de base a los accidentes, como puro sujeto de predicados. Si ese fuese el caso, aún nos moveríamos en el ámbito lógico de la predicación. Si la sustancia sólo fuera sujeto, sería lo más indeterminado, pura materia. Por ello, el Estagirita "deduce" que dicha sustancia, que es el sujeto de las determinaciones accidentales, debe tener una determinación esencial, con la que se identifica. Esto es, la sustancia es idéntica con su esencia. A este paso lo llama Inciarte "deducción trascendental de la esencia".

El sujeto de propiedades (hasta ahora, incluido tales como "hombre", sólo accidentales) no puede ser uno solo, porque si no, estaríamos otra vez en las mismas: 
las únicas determinaciones serían accidentales, pero como los accidentes no pueden ser accidentes de accidentes, seguiríamos sin orden o regulación alguna en nuestro lenguaje significativo, es decir, seguiríamos sin posibilidad de lenguaje. Los principios de orden o regularidad tienen que tener el carácter, no de accidente, sino de sujeto. Con otras palabras, tiene que haber varios sujetos o varias sustancias. Pero esto sólo es posible si cada una tiene una determinación propia o esencial. No hay accidentes de accidentes, pero sí accidentes de sustancias con sus esencias respectivas capaces de unos accidentes pero no de otros. Sólo así hay posibilidad de regularidad y, por consiguiente, de lenguaje. (Inciarte, 2004: 47, la cursiva es mía).

La cuestión de si es posible que la forma sea el sujeto de los accidentes, esto es, del mismo movimiento, ha sido tema de discusión en el ámbito de la filosofía especializada sobre Aristóteles en los últimos años. Fernando Inciarte ha bebido de esa discusión y la ha alimentado también. En la Metafísica, Aristóteles busca un nuevo sujeto para los accidentes, ya que la solución de Categorias presenta dificultades insuperables. En efecto, según el primer tratado, el individuo concreto (Sócrates blanco) es el sujeto de las demás determinaciones. Ahora bien, en cuanto que ese individuo concreto incluye dentro de sí los predicados que lo determinan, no puede ser propiamente el sujeto. Si los objetos de la experiencia incluyen las propiedades que se les atribuyen, entonces no puede ser ese mismo objeto el que subyace a dichas propiedades (Frede y Patzig: 49). E1 sujeto de las propiedades accidentales no puede incluirlas, lo cual se deriva directamente de su ser material. Esto es, si se entiende al sujeto como compuesto de materia y de forma, éste tiene ya las determinaciones que le vienen dadas por su ser material: blanco, alto, 
culto. Si bien la predicación parece admitir esta posibilidad, la pregunta por el sujeto real exige que éste no incluya ninguna propiedad accidental como tal. A diferencia de las preocupaciones de Categorías, aquí se trata de averiguar cuál es la sustancia real, no sólo cuál es nuestro modo ordinario de hablar. Por este motivo, no es exacto identificar el objeto concreto de las Categorias - este hombre o este caballo, que incluyen todas sus determinaciones- con la sustancia de la Metafísica.

Junto con otros autores, Inciarte argumenta a favor de la forma, de la esencia, como sustancia primera y particular $(1989,2004,2005,2016)^{3}$. Dicha interpretación particularista puede ser resumida de la siguiente manera: las formas sustanciales, más que los individuos concretos, son las entidades básicas en la Metafísica, es decir las sustancias. Todo lo demás, incluidos los objetos concretos, depende en su explicación de ellas. La consideración de la forma como individual no está exenta de complicaciones. Dos dificultades se presentan, al menos a primera vista: por una parte, queda problematizada la posibilidad del conocimiento científico, entendido como conocimiento de lo universal. Por otra, la interpretación de la forma como particular parece poner en peligro la comunidad específica de varios individuos, esto es, lo que en Categorías se llama sustancia segunda. La primera dificultad se plantea porque se teme que haya que concluir que no hay conocimiento posible de

${ }^{3}$ Esta tesis fue avanzada por R. Albritton y desarrollada, también, y desde ángulos distintos, por M. Frede (1985, 1987), G. Patzig (Frede y Patzig, 1988), Hartman (1977), Witt (1989), Lloyd (1981). La posición de Inciarte presenta diferencias y novedades respecto a estos autores en las que no puedo entrar aquí. 
aquello que es —es decir, de la forma — si ésta no se admite como universal. De ahí que, en el nivel gnoseológico, la afirmación de que la sustancia es la forma individual parecería implicar una posición nominalista en el Aristóteles maduro, frente a un supuesto realismo extremo presente en las Categorias o al esencialismo que de ordinario se le atribuye al Estagirita. Fernando Inciarte ha argumentado convincentemente en favor de la interpretación de la forma como particular desde esta problemática (Inciarte, 1989: 382-389), sosteniendo que la universalidad del conocimiento se funda en la analogía. Como tendré ocasión de mostrar, la analogía se configura como la herramienta cognoscitiva fundamental en la captación de los conceptos metafísimetafísicos.

En el contexto de los libros centrales de la Metafísica, la sustancia se entiende como la forma, la esencia, en contraposición a sus determinaciones accidentales. Si es así, entonces el objeto individual de la experiencia se identifica con la forma realizada en la materia, no como compuesto, por agregación, de materia y de forma. Ahora bien, tales objetos individuales de la experiencia no pueden ser los sujetos de las determinaciones porque incluyen ya ellos mismos esas determinaciones, mientras que el sujeto de las determinaciones tiene que aparecer en contraposición con ellas.

La dificultad para entender esta identificación de la forma con la sustancia tiene que ver con el modo como en algunas ocasiones se piensa la relación entre determinaciones y sujeto, siguiendo el modelo de inherencia postulado en Categorias. Efectivamente, se suele distinguir entre determinaciones esenciales y no esenciales (rastro de la distinción entre accidentes y sustancia segunda), las cuales le ocurren a un sujeto que en sí mismo parecería no tener 
ninguna determinación. En tal caso, la forma sustancial sería una determinación esencial que le sobreviene a un objeto concreto. No hay tal cosa en el horizonte de la Metafisica. Lo esencial para un objeto particular no consiste en algunas determinaciones, sino que aquello que es esencial para un objeto es lo mismo que la forma, esto es, que la sustancia. Ese algo que le resulta constitutivo es, por tanto, el mismo sujeto de las demás determinaciones, no una determinación especial (llámese esencial si se quiere), al modo de una super-determinación. La esencia no es una super-determinación, sino la sustancia misma, también en cuanto que sujeto. Como la sustancia, también la esencia está continuamente modificándose. Dice Inciarte:

A primera vista, parece más difícil aceptar la mutabilidad de la esencia que la de la sustancia. La dificultad proviene de no captar la identidad de ambas entre sí. A diferencia de la identidad de los accidentes con la sustancia, se trata aquí de una identidad necesaria o indisoluble. Es el juego de esos dos tipos de identidad lo que hay que captar adecuadamente si se quiere entender a Aristóteles (2004: 48).

La identidad entre sustancia y esencia (necesaria e indisoluble) se distingue de la identidad entre la sustancia y los accidentes o propiedades. Dichos accidentes o propiedades se identifican de manera contingente y temporal con la sustancia, esto es, con la esencia. "Yo no estoy del todo en mi mano como parte, pero sí en mi propiedad de tenerla" (Inciarte, 2016: 244, n. 44). Así, puede hablarse de que yo me identifico contingente y temporalmente con tener mi mano (no con la parte de mi cuerpo que es la mano, se entiende). Por ello, de acuerdo con Inciarte, 
...el término "inherencia" (procedente de las definiciones dadas en ese mismo capítulo segundo del Libro de las Categorías) resulta inadecuado para describir las relaciones entre sustancia (o esencia) y accidentes. El término sugiere una exterioridad (un "extrinsecismo") que amenaza con oscurecer otra vez la distinción fundamental entre parte y propiedad, por ejemplo, "pigmentum" y "color". (Inciarte, 2016: 244, n. 44).

De acuerdo con esta versión "inherentista" o "extrínseca", la sustancia (identificada con la esencia) aparece "como un núcleo inmóvil, que no se ve afectado por los cambios de accidentes que ocurren sólo a su alrededor" (Inciarte, 2016: 250). Tal sustancia o esencia inmóvil se corresponde sólo al concepto abstracto de especie, que en el griego de Aristóteles se dice también eidos, igual que la esencia como forma. Sólo la esencia en ese primer sentido (la sustancia segunda de las Categorias, esto es, la forma en sentido abstracto o ideal) es la que no se modifica.

En cambio, la forma sustancial, por ejemplo, el alma de un individuo humano, eso sí que se modifica al modificarse el individuo cuya esencia propiamente dicha o forma (sustancia) constituye y cuyas modificaciones provienen del cambio de accidentes. (Inciarte, 2016: 251).

Esto queda ya de manifiesto en la enigmática fórmula aristotélica para la esencia: to tí ên einai, "aquello que era ser". Si bien una parte de la interpretación de Aristóteles ha visto ahí restos de platonismo (la presencia de lo intemporal en el presente), Inciarte se decanta por otra interpretación, fundada en el "imperfecto filosófico" de P. Natorp. La expresión aristotélica es 
enigmática por imprecisa. Ahora, esa imprecisión parece tener un sentido buscado por el mismo Aristóteles. Inciarte la expresa así: "lo que se consigue con esa imprecisión no es tanto fijar la esencia en una fórmula, sino todo lo contrario: dejarla abierta para futuras investigaciones" (Inciarte, 2016: 253). Queda entonces claro que no estamos ante la idea de esencia como algo fijo, inmóvil, sino como aquello que en cuanto que objeto del conocimiento es provisional está siempre abierto a nuevos descubrimientos y a nuevas posibilidades. Inciarte establece aquí una analogía con el sentido de esencia como apariencia en Hegel: "la manifestación del ser en la esencia como lo que no es, no se limita al ser; se continúa en la esencia, puesto que ésta no es otra cosa que el ser vuelto apariencia" (Inciarte, 2016: 253). Y continúa recordando cómo Aristóteles había dicho en el De Anima que pretender captar definitivamente la esencia del hombre en una definición es motivo de risa, un absurdo. Así, "la esencia de las cosas no es captable al margen de las concepciones que sobre ellas se hayan ido elaborando a lo largo de la historia" (Inciarte, 2016: 254). En el mismo tratado De Anima, hay un texto que apoya máximamente esta idea. Dice Aristóteles:

Parece, sin embargo, que tener un conocimiento de lo que algo es [tó ti esti] es útil para conocer las causas de los accidentes de la sustancia [...] también, a la inversa, los accidentes contribuyen de manera notable a nuestro conocimiento de lo que algo es [ta symbebekóta sumbálletai mega méros prós tó eidénai tó ti estin]. Pues cuando somos capaces de dar cuenta, a través de la imaginación, de dichos accidentes (de todos o de la mayoría) entonces podemos dar cuenta mejor, aquí y ahora, de la sustancia. Porque el punto de partida de toda demostración es lo que algo es. Y toda definición a través de la cual no conozcamos los accidentes, o no 
los representemos fácilmente, claramente ha sido planteada dialécticamente y es vacía” (De Anima I, 1 402b16-403a2).

En este pasaje, aparece vinculado el conocimiento de la sustancia (lo que algo es) al de los accidentes, con la intermediación de la imaginación (phantasia), que no es otra que la facultad que capta las apariencia (ta fainómena) ${ }^{4}$. La definición de la esencia (siempre provisional) debe dar cuenta de los accidentes (de su modificación), pues en caso contrario, no se estaría haciendo buena ciencia. De acuerdo con el Aquinate, esta circularidad en el conocimiento de la sustancia y sus accidentes se debe a que los principios esenciales de las cosas son desconocidos para nosotros [principia essentialia rerum sunt nobis ignota] (Sentencia De Anima I, 1, n. 15).

La idea de esencia o forma sustancial como lo que era ser permite hablar precisamente de su mutabilidad, esto es, de su perfeccionabilidad y su proyección en el tiempo y, en el ámbito gnoseológico al menos, de su provisionalidad.

\section{La analogía como método "vivo" de la metafísica}

Inciarte ha insistido en que los conceptos fundamentales de la metafísica sólo se captan mediante analogías, que no tienen que ver con el qué sino con el cómo. El cambio radical de comprensión de Aristóteles que propone tam-

${ }^{4}$ Para una interpretación de este texto en línea con mucho de lo expuesto hasta ahora, cf. Carbonell, 2015. 
bien implica una nueva perspectiva respecto del método. La perspectiva epistemológica fundada en la consideración de la analogía implica buscar una unidad que no anule la diversidad: una unidad analógica y no genérica, y que, por tanto, no se predica unívocamente. Ampliar los límites de la racionalidad exige privilegiar una consideración analógica, esto es no unívoca, de la realidad.

Por ello, en el momento culminante de los libros centrales de la Metafisica, Aristóteles acude a la analogía: tò análogon synorân, que Inciarte glosa como "ver la identidad de una función común en una multiplicidad de contenidos dispersos" (Inciarte, 2016: 254-55). Se trata de esa visión sinóptica, unitaria, de la que ya hablaba Platón como máxima seña del filósofo (República 537c), si bien sin haber descubierto todo el rendimiento cognoscitivo de la analogía.

En los tratados lógicos, se privilegia el tratamiento unívoco de los conceptos: la subsunción de los predicados en géneros cada vez más amplios. Este modelo es de índole lógico y resulta inadecuado para explicar la sustancia. Los modelos de predicación basados en la univocidad resultan poco aptos para captar los conceptos metafísicos, toda vez que se mueven en el plano de la idealidad.

Junto a la predicación genérica, aparecen dos posibilidades de predicación utilizados en la Metafísica, que se corresponden con dos tipos fundamentales de homonimia de tipo no-accidental: unidad pròs hèn y kat' analogían. A la primera, la bomonimia ad unum, la tradición medieval la llamó también analogía de atribución intrínseca, y la tradición aristotélica más reciente unidad de significación focal. La analogía, a secas en Aristóteles, quedó denominada en 
la escolástica analogía de proporcionalidad, y ha quedado marginada con demasiada frecuencia al ámbito poético de la metáfora. Ambos principios metódicos, que coexisten en los textos aristotélicos, dan origen a dos tratamiento distintos de los conceptos fundamentales de la metafísica en los escritos del Estagirita.

Tanto en el caso de la analogía como en el de la significación focal, se da un uso múltiple de un mismo término que no es completamente equívoco. Mientras que la unidad de significación focal se funda en la relación que diversas cosas tienen con una (ad unum), la analogía se funda en una igualdad de proporciones que se da entre, por lo menos, cuatro términos (Poet. 21, $1457 \mathrm{~b} 16-18)^{5}$. La significación focal se diferencia de la analogía en que la primera se da cuando varios objetos — que comparten nombre - se definen a través de una relación distinta respecto a un idéntico (el primero en cada categoría), mientras que en la analogía los objetos son definidos a través de su respectiva e idéntica relación con distintos. Como lo ha expuesto F. Inciarte, por analogía ha de entenderse "identidad - y no mera semejanza- de estructura o función dentro de la diversidad de contenidos" (Inciarte, 2004: 24).

${ }^{5}$ Aunque Aristóteles defina la analogía cuando está hablando de metáfora, no pueden confundirse ambos términos, porque lo que el Estagirita dice es que hay un tipo de metáforas que se funda en la analogía, y si la analogía tiene un carácter fundante respecto de la metáfora por lo menos no hay identidad entre ambas. Cf. Poet.1457b6-11. Las metáforas fundadas en la analogía son precisamente las mejores y, además, la única que no ocurre según el género y la especie, es decir, según el esquema de universalidad genérica. Cf. también Et. Nic., 1131 a 31 ss. 
Mientras la significación focal apunta a la conexión entre las definiciones de una palabra mediante el análisis de sus significados, la analogía capta un esquema de proporcionalidad, que permite una representación de totalidad que ilumina cada uno de los contenidos de una manera nueva, viva. Aristóteles parece acercar el método analógico a cierto tipo de intuición, cuando se refiere a captar (usando un término ligado a lo visual) conjuntamente la analogía (Metaph. 1048a 35-37). Sin embargo, a diferencia de la inducción, la analogía no alcanza ningún género común, sino sólo una identidad de relación que no anula la pluralidad de los contenidos, si bien no se somete a ellos. Ahora bien, aunque propiamente no hay en Aristóteles camino fuera del lenguaje, sí que hay intentos de escapar de su aprisionamiento. La analogía o predicación metafísica es precisamente una herramienta conceptual de esa tentativa, y así se revela de manera evidente que dichos intentos pasan siempre a través del lenguaje, pero lo trascienden.

La analogía supone en Aristóteles, una comprensión proyectada hacia nuevas posibilidades (incluso también de corrección) capaz de superarse siempre a sí misma. El paso de la univocidad a la analogía en Aristóteles "muestra la imposibilidad de contentarse jamás con resultados ya logrados de una vez para siempre y que sólo de caso en caso necesiten ser aplicados de una manera externa sin modificación alguna y "sin vida": sin tener en cuenta el contexto, o sea su "asiento en la vida"” (Inciarte, 2016: 284).

Este "asiento en la vida", que llevará a Inciarte a transitar el camino analógico- de vaciamiento de contenido desde los contenidos significativos hasta el acto puro, presenta un peligro de naufragio para la razón "porque para ella los contenidos significativos son precisamente la medida de la inte- 
ligibilidad" (Inciarte, 2016: 307). El salto de la inteligencia más allá del concepto, esto es, la posibilidad de la inmediatez cognoscitiva que sólo se logra rompiendo el cerco de la idealidad (lo más alejado si cabe de la actitud natural del conocimiento), sólo parece posible si se abre espacio a la analogía. Esto es, el abandono de los contenidos significativos implica el abandono de la doctrina lógica de la univocidad, del pensamiento genérico, de lo puramente ideal.

Indudablemente en todo esto hay mucho elemento metafórico. Pero eso sólo puede asustar a una filosofía que siga apegada a los puros contenidos significativos, a "qués" unívocos, sin haber dado lugar (joreîn) a los "cómos" del pensamiento más depurado de la analogía, donde "analogía" significa algo eminentemente riguroso: identidad de estructura funcional independientemente del contenido de que se trate en cada caso (Inciarte, 2016: 308-9).

Aplicar una razón analógica a las cuestiones humanas últimas —en este caso, a la fe, a la cultura y a la misma comprensión de lo divino desde la filosofía- no implica falta de rigor, precisamente porque, como hace notar Aristóteles, el método lógico que corresponde a cada cuestión es diferente (Ét. Nic. I, 3, 1094b24-26), y su rigor depende de que el método resulte adecuado a su propio objeto, no siendo posible medir la racionalidad por parámetros unívocos. El carácter histórico y contingente del ámbito en el que acontecen las relaciones entre fe y razón, así como la dimensión trascendente implícita en la fe, no sólo justifican, sino que exigen una racionalidad analógica. Para hablar de lo divino y de lo humano - y más aún, de lo divino hecho humano, lo propiamente cristiano- el lenguaje humano necesita 
herramientas conceptuales que, sin dejar de ser lingüísticas, permitan escapar del aprisionamiento de un lenguaje puramente unívoco. Así, se propone frente a una racionalidad unívoca — que se identifica a sí misma como científica y que, como se ha querido mostrar, domina en el terreno de la idealidad - una racionalidad analógica, con "asiento en la vida". Precisamente cuando la razón busca hacerse inequívoca, tropieza con sus propios límites y pierde toda capacidad de superarlos.

\section{Bibliografia}

Albritton, R. (1957) "Form of particular substances in Aristotle's Metaphysics", Journal of Philosophy, 54, pp. 699-708.

Aquino, T., Sentencia libri De Anima, Textum Taurini 1959 editum ac automato traslatum a Roberto Busa SJ in taenias magneticas denuo recognovit Enrique Alarcon atque instruxit (http://www.corpusthomisticum. org/can1.html).

Aristóteles (1966) Categoriae et Liber de interpretatione, ed. L. Minio Paluello, Oxford: Clarendon.

—, (1970). Aristotelis Ethica Nicomachea [EN], Bywater, I. (ed.). Oxford: Clarendon Press, 1970.

—, (1970) Metafísica, ed. trilingüe y trad. V. García-Yebra, Madrid: Gredos.

—, (1978) Acerca del alma, trad. T. Calvo Martínez, Madrid: Gredos.

Aubenque, P. (1974), El problema del ser, Madrid: Taurus.

Buchheim, T. (2008) “'Dancing Matter” and the Stable Form. Remarks on Substance and Form in Aristotle's Metaphysics", Soochow Journal of Philosophical Studies, 18, pp. 1-21.

Carbonell, C. (2007) Movimiento y forma en Aristóteles, Pamplona: Eunsa. 
Carbonell, C. (2015) “Aristóteles imagina 'lo que es'. Dialéctica y fantasía en el origen del conocimiento", Pensamiento 71 (267), pp. 645-658.

Dumoulin, B. (1983) "L'ousia dans les Catégories et dans la Métaphysique" en Moreaux, P., Wiesner, J. (eds) Zweifelhaftes im Corpus Aristotelicum: Studien zu einigen Dubia, Berlin: Walter de Gruyter, pp. 57-72.

Driscoll, J. (1981) "Eidê in Aristotle's Earlier and Later Theories of Substance" en O’Meara, D. J. Studies in Aristotle, Washington: Catholic University of America, pp. 129-159.

Frede, M. (1985), "Substance in Aristotle's Metaphysics" en Gotthelf, A. (ed.) Aristotle on Nature and Living Things, Pittsburgh: Mathesis, pp. 17-26.

-, (1987), Individuals in Aristotle. Essays in ancient philosophy, Oxford: Clarendon Press, pp. $49-71$.

Frede, M., \& Patzig, G. (1988), Aristoteles 'Metaphysik Z'. Tezt, Übersetzung und Kommentar, Bd. I-II, München: Beck.

Hafemann, B. (1998), Aristoteles' Transzendentaler Realismus. Inhalt und Umfang erster Prinzipien in der "Metaphysik", Berlin/Nueva York: De Gruyter.

Hartman, E. (1977), Substance, Body and Soul. Aristotelian Investigations, Princeton: Princeton University Press.

Inciarte, F. (1970), Forma Formarum. Strukturmomente der Thomistischen Seinslehre im Rückgriff auf Aristoteles, Freiburg-München: K. Alber.

Inciarte, F. (1989), "Für und wider den Nominalismus", Philosophisches Jabrbuch, 1989, pp. 382-393.

—, (1993), "La identidad del sujeto individual según Aristóteles", Anuario Filosófico 26, pp. 289-302.

—, (2004) Tiempo, sustancia, lenguaje. Ensayos de Metafisica (ed. L. Flamarique), Pamplona: Eunsa.

—, (2016) Cultura y verdad (ed. L. Flamarique), Pamplona: Eunsa. 
Claudia Carbonell

—, (s/f) "Sobre la importancia de lo vero-símil y de la imaginación en el mito platónico para la captación del mundo como imagen de las ideas", pro manuscripto.

一, (s/f) Vorlesungen WS '77/78: Plato, pro manuscripto.

Lloyd, G.E.R. (1968), Aristotle: the growth and structure of his thought, Cambridge: Cambridge University Press.

Pasnau, R. (2011), Metaphysical Themes: 1274-1671, Oxford: Clarendon Press.

Platón (1983), Crátilo en Diálogos II, Madrid: Gredos.

Scaltsas, T. (1994), “Substancial holism” en Scaltsas, T., Charles, D. y Gill, M.L. (eds.) Unity, Identity, and Explanation in Aristotle's Metaphysics, Oxford: Clarendon Press.

Witt, C. (1989), Substance and Essence in Aristotle, Ithaca: Cornell University Press.

Claudia Carbonell claudia.carbonell@unisabana.edu.co 